\title{
The Influence of the Melt-Pouring Temperature and Inoculant Content on the Macro and Microstructure of the IN713C Ni-Based Superalloy
}

\author{
HUBERT MATYSIAK, ${ }^{1}$ MALGORZATA ZAGORSKA, ${ }^{2,6}$ ALICJA \\ BALKOWIEC, ${ }^{2}$ BOGUSLAWA ADAMCZYK-CIESLAK, ${ }^{2}$ KRZYSZTOF \\ DOBKOWSKI, ${ }^{2}$ MATEUSZ KORALNIK, ${ }^{2}$ RAFAL CYGAN,${ }^{3}$ JACEK \\ NAWROCKI, ${ }^{4}$ JAN CWAJNA, ${ }^{5}$ and KRZYSZTOF J. KURZYDLOWSKI ${ }^{2}$
}

\begin{abstract}
1.-Functional Materials Research Center, Warsaw University of Technology, 02-507 Warsaw, Poland. 2.-Faculty of Materials Science and Engineering, Warsaw University of Technology, 02-507 Warsaw, Poland. 3.-Wytwornia Sprzetu Komunikacyjnego PZL Rzeszow S.A., 35-078 Rzeszow, Poland. 4.-Faculty of Mechanical Engineering and Aeronautics, Rzeszow University of Technology, 35-959 Rzeszow, Poland. 5.-Faculty of Materials Engineering and Metallurgy, Silesian University of Technology, 40-019 Katowice, Poland. 6.-e-mail: m.zagorska@inmat.pw. edu.pl
\end{abstract}

\begin{abstract}
The aim of this work was to determine the effect of melt-pouring temperature $T_{\mathrm{m}}$ and inoculant (cobalt aluminate- $-\mathrm{CoAl}_{2} \mathrm{O}_{4}$ ) concentration in the prime coat of the shell mold on the macro- and microstructure of the IN713C superalloy. The results show that cobalt aluminate is an effective modifier of the IN713C superalloy, which causes refinement of the equiaxed grains (EX) and a reduction of the fraction and size of the columnar grains on the casting surface. Also, the melt-pouring temperature in the range of $1450-1520^{\circ} \mathrm{C}$ was found to influence the mean EX grain size. Based on the results of differential thermal analysis of the alloy and detailed microstructure characterization, a sequence of precipitations has been proposed that advances current understanding of processes that take place during alloy solidification and casting cooling.
\end{abstract}

\section{INTRODUCTION}

IN713C is a nickel-based superalloy adequate for use at high temperatures. Its good resistance to high-temperature corrosion and creep, good castability, and high structural stability at elevated temperature ${ }^{1-7}$ make it suitable for fabrication; therefore, this superalloy is widely used in aircraft engine turbines parts, ${ }^{4,5,8,9}$ such as low-pressure turbine (LPT) blades and LPT vane clusters. For example, the designers of the large aircraft turbofan engine GP7200 selected this alloy for the production of LPT blades and LPT vane clusters. These complicated castings must meet all quality requirements, which in this case are highly strict. Every IN713C superalloy master ingot has to undergo a number of tests. Examined are the chemical composition (the content of the main alloying elements and the trace elements) and the mechanical properties (employing static tensile testing at elevated temperatures and stress rupture tests).
The as-cast IN713C superalloy has a dendritic microstructure. The matrix of the alloy is the $\gamma$ phase, strengthened by cubic and coherent precipitations of the $\gamma^{\prime} \mathrm{Ni}_{3}(\mathrm{Al}, \mathrm{Ti})$ phase. ${ }^{1,2,10,11}$ Carbon present in the alloy segregates into the interdendritic areas and reacts with carbide-forming elements, such as niobium, titanium, or tantalum, thus, forming metal carbides (MC) with the NbC structure. ${ }^{1,2,10-14}$ To obtain optimal mechanical properties of the IN713C alloy, it is common practice to maximize the volume fraction of the $\gamma^{\prime}$ phase and to promote a uniform EX grain size distribution. This can be achieved by proper selection of melting and pouring parameters, as well as by inoculation. ${ }^{15-18}$

The predominant feature of investment cast superalloys is the macrostructural coarseness and nonuniformity of surface grain size, which may reduce the fatigue performance and reliability of cast LPTs in the intermediate temperature range. In the LPT section, the operating temperature is within the range of $650^{\circ} \mathrm{C}$ and $700^{\circ} \mathrm{C}$, which is usually below the 
creep range where stresses from centrifugal loads are high. Thus, high tensile strength and good low cycle fatigue (LCF) resistance are primarily required. In this temperature range, a uniform and relatively fine surface grain size is desired to promote fatigue properties and resistance to crack growth. ${ }^{19-23}$ For this reason, in the presented work, castings were modified by adding the $\mathrm{CoAl}_{2} \mathrm{O}_{4}$ inoculant to the prime coat of the shell mold. This technique of modification was chosen due to the ease of implementation, the acceptable cost, and satisfactory results (for thin-wall castings), in accordance with the requirements put forward by turbine parts purchasers. The modification mechanism of the nickel superalloys with the use of the cobalt aluminate is widely discussed in the literature. ${ }^{19-24}$ The alloying elements (e.g., $\mathrm{Cr}, \mathrm{C}, \mathrm{Ti}$, and $\mathrm{Al}$ ) react with $\mathrm{CoAl}_{2} \mathrm{O}_{4}$ to form $\mathrm{Co}$ particles formed on the surface of the shell mold. The particles act as nucleation sites for the heterogeneous crystallization of the $\gamma$ phase. The crystallographic similarity and low value of lattice misfit between the nucleation sites and $\gamma$ phase guarantee effective refinement of the surface macrograins. ${ }^{25}$

The aim of the current research was to determine the effect of the melt-pouring temperature and the inoculant concentration (cobalt aluminate) in the prime coat of the shell mold on the macro- and microstructure of IN713C superalloy castings.

\section{MATERIAL AND EXPERIMENTAL PROCEDURE}

The IN713C superalloy was provided by Canon Muskegon. The chemical composition of the alloy is presented in Table I.

As-received "master heat" ingots were cut into charges of $3.5 \mathrm{~kg}$. These were later melted in a zirconia ramming crucible installed in the industrial VIM IC Consarc furnace. General technical conditions of the casting trials are listed in Table II.
Vacuum during melting and pouring was maintained at a level of $2 \times 10^{-2}$ mbar. Three meltpouring temperatures $\left(T_{\mathrm{m}}\right)$ were used: $1450^{\circ} \mathrm{C}$, $1480^{\circ} \mathrm{C}$, and $1520^{\circ} \mathrm{C}$, which were controlled by $\mathrm{Pt} /$ $\mathrm{Pt}-\mathrm{Rh}$ thermocouples. The molten alloy was cast into ceramic shell molds fabricated through the "dip and stucco" technique. The assembly consisted of five plate cast samples, each of $0.2 \mathrm{~kg}$ with a height of $100 \mathrm{~mm}$, a width of $70 \mathrm{~mm}$, and a wall thickness of $5 \mathrm{~mm}$.

Three different prime coats of shell molds were used for the casting trials:

a) Trials 1-3: with a zircon filler and colloidal silica binder.

b) Trials 4-6: same as Trials 1-3 plus 5 wt.\% of cobalt aluminate $\left(\mathrm{CoAl}_{2} \mathrm{O}_{4}\right)$ inoculant.

c) Trials 7-9: same as Trials 1-3 plus $10 \mathrm{wt} \%$ of cobalt aluminate $\left(\mathrm{CoAl}_{2} \mathrm{O}_{4}\right)$ inoculant.

Alumina silicate powders were applied as a shell mold backup. The molds were dewaxed in boilerclave, burned out at $750^{\circ} \mathrm{C}$, heat insulated with alumina-silicate Fiberfrax $^{\circledR}$, and fired in air at $1250^{\circ} \mathrm{C}$ for $2 \mathrm{~h}$. During the pouring process, the temperature of all the shell molds $\left(T_{\mathrm{s}}\right)$ was $1200^{\circ} \mathrm{C}$. The temperature changes during the alloy solidification and casting cooling were evidenced using $\mathrm{Pt} /$ $\mathrm{Pt}-\mathrm{Rh}$ thermocouples and the multichannel recorder HIOKI. By using these data, the average cooling rate was calculated in the temperature range from $T_{\mathrm{m}}$ to $650^{\circ} \mathrm{C}$. Regardless of the $T_{\mathrm{m}}$ measured, the average cooling rate at the center of the castings was within the range of $10-12^{\circ} \mathrm{C} / \mathrm{min}$.

To estimate the main temperature characteristics during solidification of the IN713C superalloy, differential thermal analysis (DTA) was performed by using Labsys DTA/DSC Staram. Specimens weighing $0.14 \mathrm{~g}$ were cooled from $1500^{\circ} \mathrm{C}$ to $500^{\circ} \mathrm{C}$ under a flowing argon atmosphere at a cooling rate of $10^{\circ} \mathrm{C} /$

Table I. Chemical composition of the IN 713C superalloy

\begin{tabular}{lllllllllllll}
\hline $\begin{array}{l}\text { Element } \\
\text { wt.\% }\end{array}$ & $\mathbf{C}$ & $\frac{\mathbf{S i}}{0.069}$ & $\frac{\mathbf{A l}}{0.010}$ & $\frac{\mathbf{B}}{6.080}$ & $\frac{\mathbf{N b}+\mathbf{T a}}{0.010}$ & $\frac{\mathbf{C r}}{2.160}$ & $\frac{\mathbf{F e}}{13.580}$ & $\frac{\mathbf{M o}}{0.090}$ & $\frac{\mathbf{T i}}{4.210}$ & $\frac{\mathbf{Z r}}{0.840}$ & $\frac{\mathbf{N i}}{0.060}$ \\
\hline
\end{tabular}

Table II. Technical conditions of the casting trials

\begin{tabular}{|c|c|c|c|}
\hline \multirow[b]{3}{*}{ Shell mold system and firing temperature $\left(T_{\mathrm{s}}\right)$} & \multicolumn{3}{|c|}{ Melt-pouring temperature, $T_{m}\left({ }^{\circ} \mathrm{C}\right)$} \\
\hline & \multicolumn{3}{|c|}{ Trial acronym } \\
\hline & $\underline{1450}$ & 1480 & $\underline{1520}$ \\
\hline 0 wt. $\%$ of $\mathrm{CoAl}_{2} \mathrm{O}_{4}$ inoculant, $T_{\mathrm{s}}=1200^{\circ} \mathrm{C}$ & $\mathrm{T} 1$ & $\mathrm{~T} 2$ & T3 \\
\hline 5 wt. $\%$ of $\mathrm{CoAl}_{2} \mathrm{O}_{4}$ inoculant, $T_{\mathrm{s}}=1200^{\circ} \mathrm{C}$ & $\mathrm{T} 4$ & T5 & T6 \\
\hline 10 wt. $\%$ of $\mathrm{CoAl}_{2} \mathrm{O}_{4}$ inoculant, $T_{\mathrm{s}}=1200^{\circ} \mathrm{C}$ & $\mathrm{T} 7$ & $\mathrm{~T} 8$ & T9 \\
\hline
\end{tabular}


Macrostructure (d2)

Microstructure (LM, SDAS, SEM+EDS, TEM)

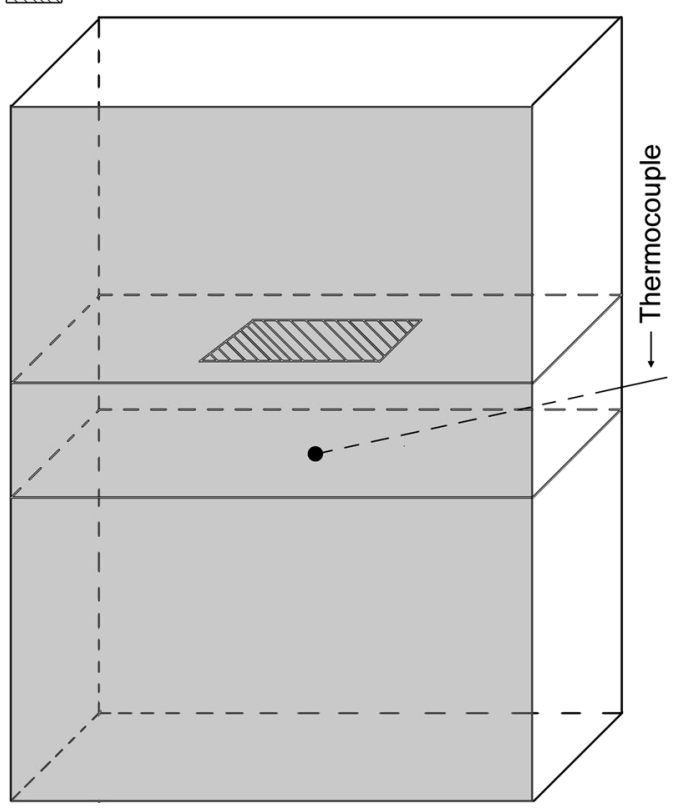

Fig. 1. Sampling areas for macro- and microstructure investigations.

min. A $99.99 \%$ pure corundum was used as the reference material. The enthalpy of the observed transformations during solidification and casting cooling were determined by measuring the exothermic peak areas with a numerical integrator method.

The surface of the cast plates (Fig. 1) were macroetched with a solution of analytically pure $\mathrm{HNO}_{3}$ (20 g/L), $\mathrm{HCl}(300 \mathrm{~g} / \mathrm{L}), \mathrm{FeCl}_{3}(160 \mathrm{~g} / \mathrm{L})$, and $\mathrm{H}_{2} \mathrm{O}$ $(100 \mathrm{~mL} / \mathrm{L})$ at $50^{\circ} \mathrm{C}$ (time of etching was $\left.2-4 \mathrm{~min}\right)$. A digital microscope (VHX Kayence) was used to capture the macrostructure images. Image processing and quantitative image analyses were performed by using MicroMeter software. ${ }^{26}$ The size of the macro grains on the surface of the castings was measured in terms of equivalent grain diameter $d_{2}$ (diameter of a circle with the same surface area). An average value of $d_{2}$, out of 100 equiaxed surface macro grains, was obtained for each of five castings from each assembly.

Microstructure characterization and analyses were carried out by using the following techniques: light microscopy (LM) equipped with Vickers microhardness device $(\mu \mathrm{HV})$, scanning electron microscopy (SEM), transmission electron microscopy (TEM), and x-ray spectroscopy (EDS).

The samples for LM and SEM observations were sectioned along the transverse cross section of the cast plates (Fig. 1). The specimens were then ground, polished, and chemically etched with Kalling's reagent, consisting of analytically pure 5-g $\mathrm{CuCl}_{2}, 100-\mathrm{mL} \mathrm{HCl}$, and 100-mL ethanol. The dendritic microstructure and the secondary dendrite arm spacing (SDAS) were investigated in the center of the cross-sectioned samples by using a Nikon Epiphot 220 LM and were quantitatively analyzed by employing MicroMeter software. The sample cross sections were also analyzed by a SEM Hitachi S-3500 N equipped with energy-dispersive x-ray spectroscopy (EDS). For the imaging and EDS analyses, a $15-\mathrm{kV}$ accelerating voltage was used. SEM microstructure images were analyzed quantitatively in terms of the $\gamma^{\prime}$ phase size in dendrites and interdendritic areas. An equivalent diameter $d_{2}$ of the $\gamma^{\prime}$ phase was measured.

Samples for TEM observations of the IN713C matrix were cut from 3-mm-diameter cylinders cut from the castings by spark erosion. Thin foils of $0.2-\mathrm{mm}$ thickness were sliced by a wire saw and mechanically grounded using a Gatan Dimple Grinder. Finally, thin foils were electrochemically polished by the double-jet method on a Struers device in a mixture of acetic and perchloric acids (95/5 vol.\%). Samples for TEM observations of the IN713C superalloy constituents $\left(\mathrm{M}_{3} \mathrm{~B}_{2}\right.$ and $\left.\mathrm{Ni}_{7} \mathrm{Zr}_{2}\right)$ were prepared by using a single focused ion beam (FIB) system (Hitachi FB-2100) and a lift-out preparation technique. The sampling area was selected on the basis of SEM observations. The obtained material underwent microstructure observations and selected area electron diffraction analyses (SAED), which were performed with a Jeol JEM 1200EX II TEM (operating at $120 \mathrm{kV}$ ). The diffraction aperture with a diameter of $500 \mathrm{~nm}$ was used.

\section{RESULTS}

\section{Differential Thermal Analysis (DTA) Results}

The results of the DTA of the IN 713C superalloy are shown in Fig. 2 and Table III.

The cooling curve exhibits an exothermic peak with two maxima related to solidification processes. The beginning of the solidification (formation of $\gamma$ phase dendrites, $\mathrm{L} \rightarrow \gamma$ ) was recorded at $T_{1}=1342^{\circ} \mathrm{C}$ - the liquidus temperature. The maximum at which the transformation occurs with the highest intensity is at $T_{2}=1338^{\circ} \mathrm{C}$. The second maximum is related to the precipitation of $\mathrm{MC}$ primary carbides from the liquid ( $\rightarrow$ MC) and the formation of the $\mathrm{MC} / \gamma$ eutectic $(\mathrm{L} \rightarrow \mathrm{MC}+\gamma)$. This transformation begins at $T_{3}=1305^{\circ} \mathrm{C}$, and its maximum is observed at $T_{4}=1299^{\circ} \mathrm{C}$. The solidification ends at $T_{5}=1263^{\circ} \mathrm{C}$-the solidus temperature. The solidification enthalpy $\left(\Delta H_{\mathrm{SOL}}\right)$ can be estimated as $-125 \mathrm{~J} / \mathrm{g}$. During the cooling, a minor effect was also observed related to an exothermic transformation in the solid state with a maximum at $\mathrm{T}_{7}=1151^{\circ} \mathrm{C}$. This is caused by the precipitation of $\gamma^{\prime}$ phase from $\gamma$ phase $\left(\gamma \rightarrow \gamma^{\prime}\right)$, which starts at $T_{6}=1169^{\circ} \mathrm{C}$ and ends at $T_{8}=929^{\circ} \mathrm{C}$. The enthalpy of the phase transformation $\left(\Delta H_{\gamma}{ }^{\prime}\right)$ in the solid state equals $-9 \mathrm{~J} / \mathrm{g}$. Further cooling of the alloy below $929^{\circ} \mathrm{C}$ does not cause any significant thermal effects on the DTA curve. 


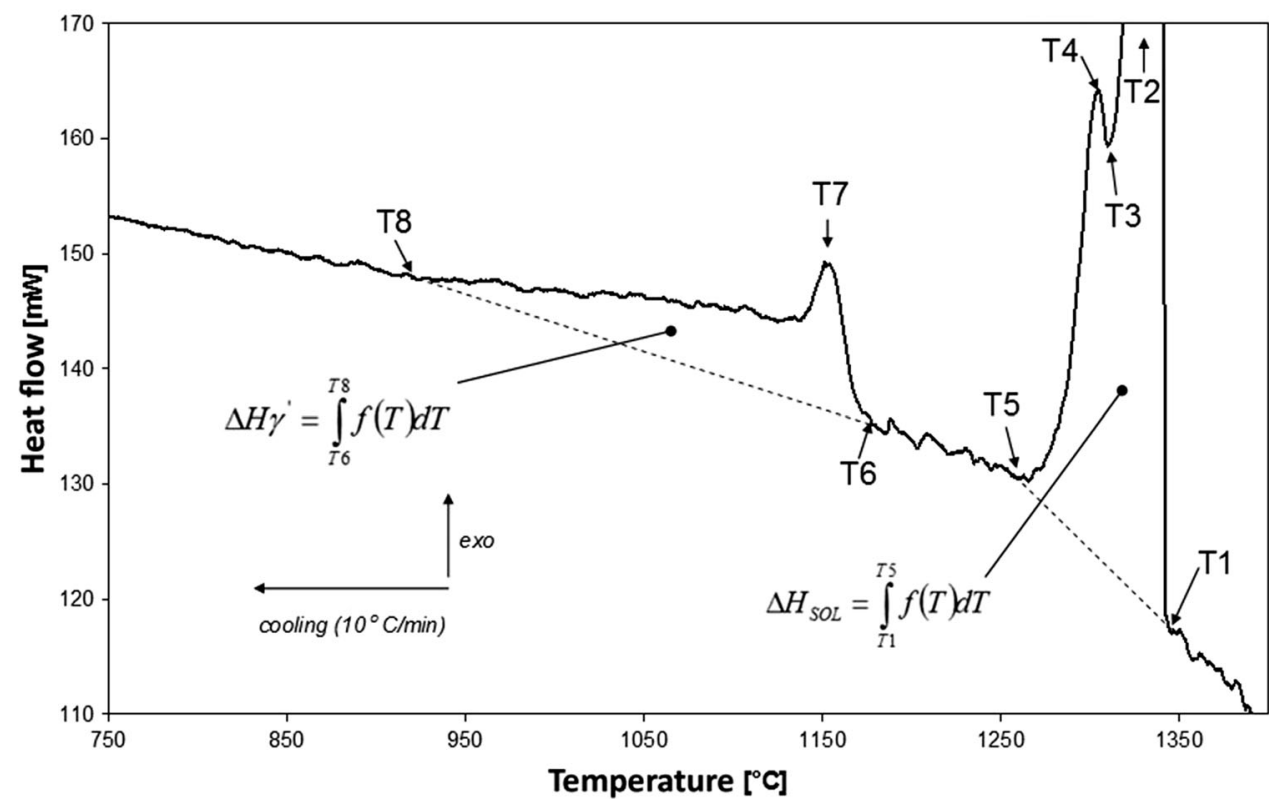

Fig. 2. DTA curve (cooling range) for the IN713C superalloy obtained at a cooling rate of $10^{\circ} \mathrm{C} / \mathrm{min}$ in the temperature range $1400^{\circ} \mathrm{C}$ to $750^{\circ} \mathrm{C}$.

Table III. DTA results for the IN $713 \mathrm{C}$ superalloy

\begin{tabular}{|c|c|c|c|c|c|}
\hline \multirow{2}{*}{$\frac{\text { Transformation }}{\text { Alloy solidification }}$} & & & & ${ }^{\circ} \mathbf{C} / \mathbf{m i n}$ & \\
\hline & $T_{1}$ liquidus & ${ }^{\circ} \mathrm{C}$ & 1342 & 1335 & 1338 \\
\hline & $T_{4}$ & & 1299 & 1278 & 1238 \\
\hline & $T_{5}$ solidus & & 1263 & 1235 & 1219 \\
\hline & $\Delta H_{\mathrm{SOL}}$ & $\mathrm{J} / \mathrm{g}$ & -125 & Not given & Not given \\
\hline \multirow{3}{*}{ Solid phase trasformation } & $T_{6}$ & ${ }^{\circ} \mathrm{C}$ & 1169 & 1135 & 1175 \\
\hline & $T_{7}$ & & 1151 & Not given & Not given \\
\hline & $T_{8}$ & & 929 & 700 & 996 \\
\hline
\end{tabular}

The temperatures determined from the DTA measurements are generally in agreement with the literature data (Table III). Observed scatter of data is influenced by several factors, which can be divided into three categories: (I) associated with the DTA device, (II) associated with the sample, and (III) associated with the "interpretation" of the DTA thermogram. ${ }^{28,29}$

For the first, one can distinguish uncorrectable and variable parameters. Uncorrectable parameters are those that are connected with the design of the DTA device components. The uncorrectable parameters are not taken into consideration here. In the group of variable parameters, the cooling/heating rates and the type of atmosphere are the most important. If the cooling/ heating rates (the basic factor determining the location of characteristic temperatures on a thermogram) are the same, the type of atmosphere used and its flow rate may influence the data. For the second, the most important factors affecting the results are the mass of the tested sample (varying in discussed works), its chemical composition, and the type of reference material. The mass of the test sample has to be selected in such a way that the temperature gradient in the sample during the measurements is as low as possible. Thus, for different DTA devices, sample masses may vary; however, all of them are low and within the range of tens to hundreds of milligrams. In the case of 


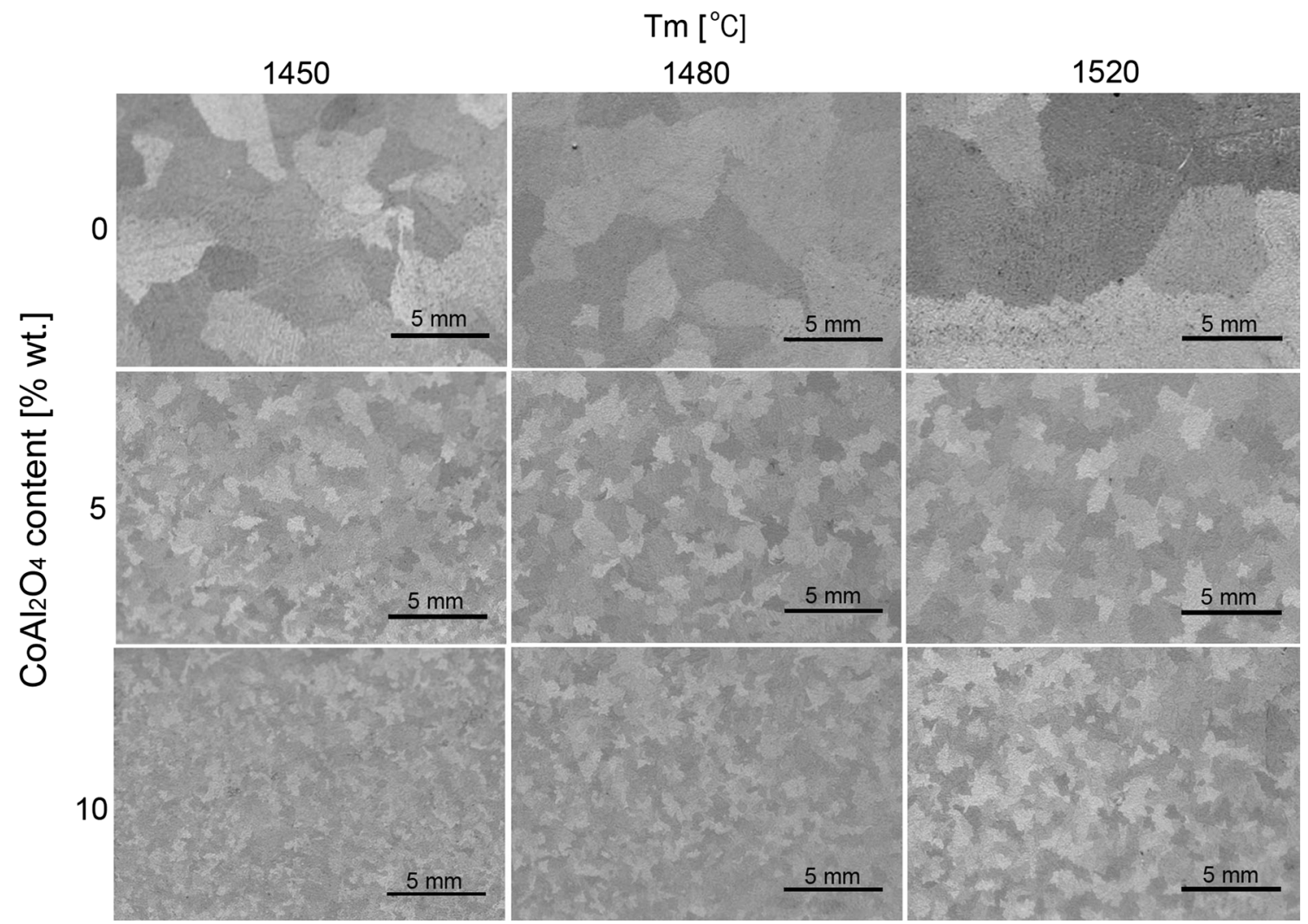

Fig. 3. Representative macrostructure images (LM) of the cast surface after sand blasting and etching.

multicomponent as-cast alloys, such a small volume of material should be considered unrepresentative due to local changes in the chemical composition caused by the segregation of alloying elements. In addition, the content of individual alloying elements, including trace elements, may vary in the ranges provided by the standard for a particular alloy grade. These differences occur in the discussed cases. Ceramic and metallic materials, in which there are no phase transitions in the range of temperature measurements, are successfully used as reference samples for the DTA technique. These materials, however, are characterized by significantly different thermal properties (such as heat capacity and thermal conductivity), which may result in noticeable differences in the obtained results. For instance, in Ref. 29, a solution suggested to increase measurement accuracy is to use platinum as a reference for defining characteristic temperatures during the melting and solidification of superalloys and to employ nickel as a reference for analyzing phase transformations in the solid state.

Finally, the "interpretation" of the DTA thermogram stems from the fact that each superalloy reaction occurs over a temperature range. Determining the onset and completion of a reaction may differ in various studies. Usually, the beginning of a reaction will be the point at which the DTA curve departs from the baseline. In the case of the end of a reaction, similarly as in the case of the beginning of a reaction, the literature points out that some researchers assume that the end is determined by the point at which the curve returns to the baseline (like in the present study), while according to others, a reaction ends at the minimum or maximum of the reaction peak. All of the aforementioned factors significantly influence the obtained results and should be taken into consideration in a comparative analysis.

\section{Macro- and Microstructure Analysis}

Microstructure images representative of the surface of the castings are presented in Fig. 3. The results of the surface grain size measurements versus the melt-pouring temperature and the cobalt aluminate content are shown in Fig. 4. On the basis of the obtained results, it should be stated that increasing the melt-pouring temperature from $T_{\mathrm{m}}=1450^{\circ} \mathrm{C}$ to $T_{\mathrm{m}}=1520^{\circ} \mathrm{C}$ causes an increase in the grain size. In the case of unmodified castings, the grain size increased 2.3 times, whereas for modified castings, it was 1.8 and 1.4 times for 5 wt.\% and 10 wt.\% inoculant content, respectively.

The results also show that the cobalt aluminate $\left(\mathrm{CoAl}_{2} \mathrm{O}_{4}\right)$ is a very effective modifier for the alloy IN713C in the whole range of melt-pouring temperatures. It both refines the equiaxed grains (EX) and significantly reduces the size and fraction of the 


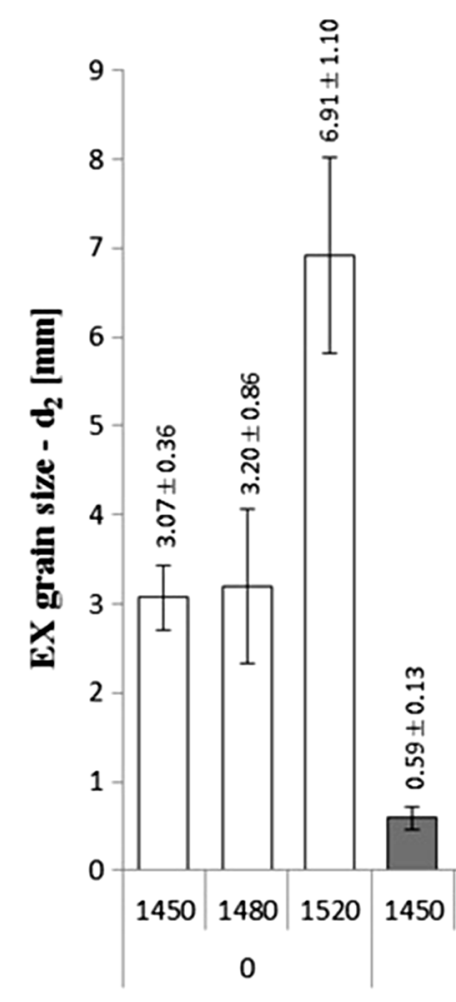

(a)

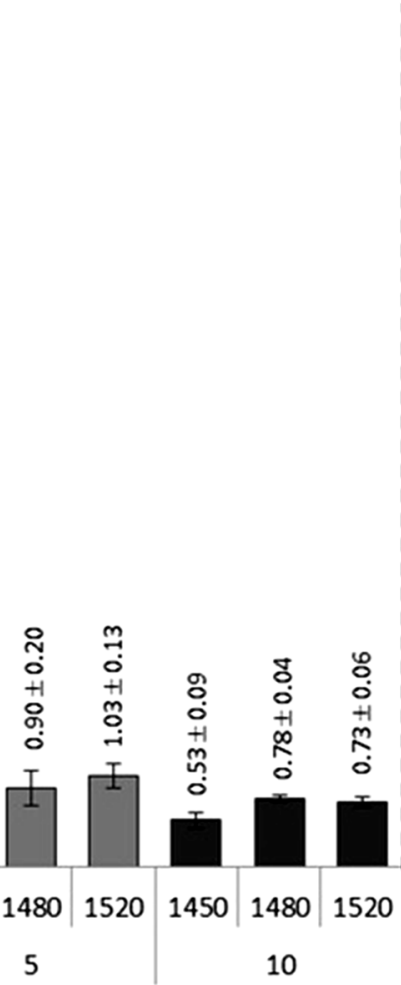

(b)

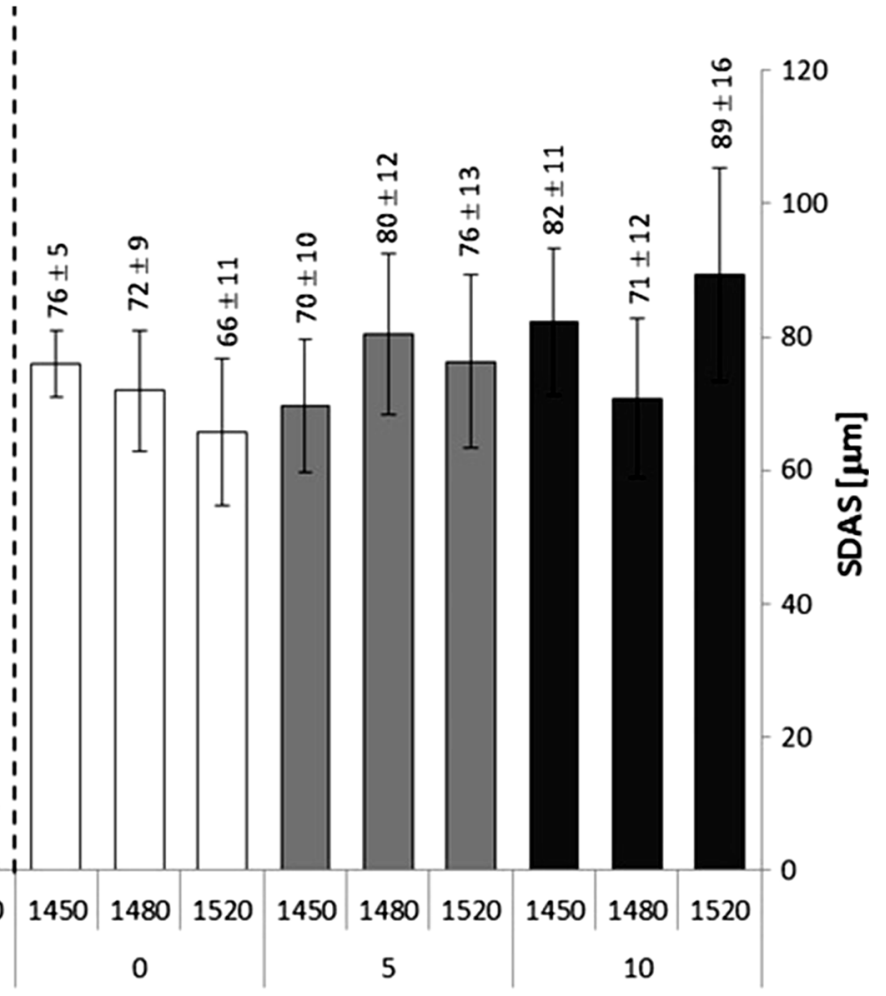

$\mathrm{Tm}\left[{ }^{\circ} \mathrm{C}\right] /$ inoculant content [\%wt.]

Fig. 4. Effect of inoculant content and melt-pouring temperature on the size of surface EX grains (a) and secondary dendritic arm spacing (SDAS) (b).

columnar ones. It should, however, be noted that the increase of the inoculant concentration from 5 wt.\% to 10 wt.\% brings about only a minor improvement.

The LM and SEM microstructure observations of the casting cross sections indicated (regardless of the melt-pouring temperature and the inoculant content) the presence of a dendritic microstructure typical of the as-cast state. Dendrites of the $\gamma$ phase and interdendritic areas with numerous precipitations were observed, as illustrated in Fig. 5a and b.

MC primary carbides, rich in $\mathrm{Nb}$ (Figs. $5 \mathrm{~b}-\mathrm{e}$ and $6 a)$, appear in large numbers in the interdendrictic areas. They occur in the form of "Chinese script" and in a eutectic mixture $\gamma+$ MC. In a few NbC carbides, one could observe oxide nonmetallic inclusions containing $\mathrm{Al}$ and $\mathrm{Mg}$ (Figs. 5e and 6b), which were probably present in the "master heat" ingot as an "impurity" after manufacturing of the alloy ingots. The $\gamma+\gamma^{\prime}$ eutectic (Fig. 5d and f) and a eutectic, in which one of the phases is rich in $\mathrm{Ni}$ and $\mathrm{Zr}$ (Figs. 5c, d and 6c), were also found. In the vicinity of this eutectic, particles of a phase $M_{3} B_{2}$ rich in Mo (Figs. 5c and 6d), eutectic $\gamma+\gamma^{\prime}$, and MC constituents (Fig. 5c and d) were observed.

The images of the dendritic structure (Fig. 5a) have been analyzed with the purpose of determining the secondary dendrite arm spacings (SDAS). The obtained results are presented in Fig. 4. No evidence for correlation between SDAS and the meltpouring temperature or the inoculant content was found. The mean values of SDAS are within the range of $66-89 \mu \mathrm{m}$.

Still, one may observe a significant difference in the microhardness values between the dendrites and the interdendritic areas, as shown in Fig. 7. Regardless of the pouring temperature and the inoculant content, a higher hardness value was recorded in the interdendritic regions, from 351 HV0.2 to 401 HV0.2 compared with 314 HV0.2 to 347 HV0.2 for the dendrites.

The increased microhardness of the interdendritic areas is connected with the segregation of the alloying elements taking place during solidification. The interdependence was confirmed by measurement of the chemical composition (EDS). The values of the segregation coefficient $k,{ }^{2}$ compiled in Table IV, indicate significant enrichment of the interdendritic areas $(k<1)$ with $\mathrm{Mo}$ and $\mathrm{Nb}$. Chromium also has a tendency to segregate to the interdendritic regions, whereas $\mathrm{Al}$ enriches the cores of the dendrites $(k>1)$.

The segregation of the alloying elements during solidification also affects the size of the $\gamma^{\prime}$ phase precipitations. Regardless of the pouring temperature and the inoculant content, coarser precipitations 
The Influence of the Melt-Pouring Temperature and Inoculant Content on the Macro and Microstructure of the IN 713c Ni-Based Superalloy
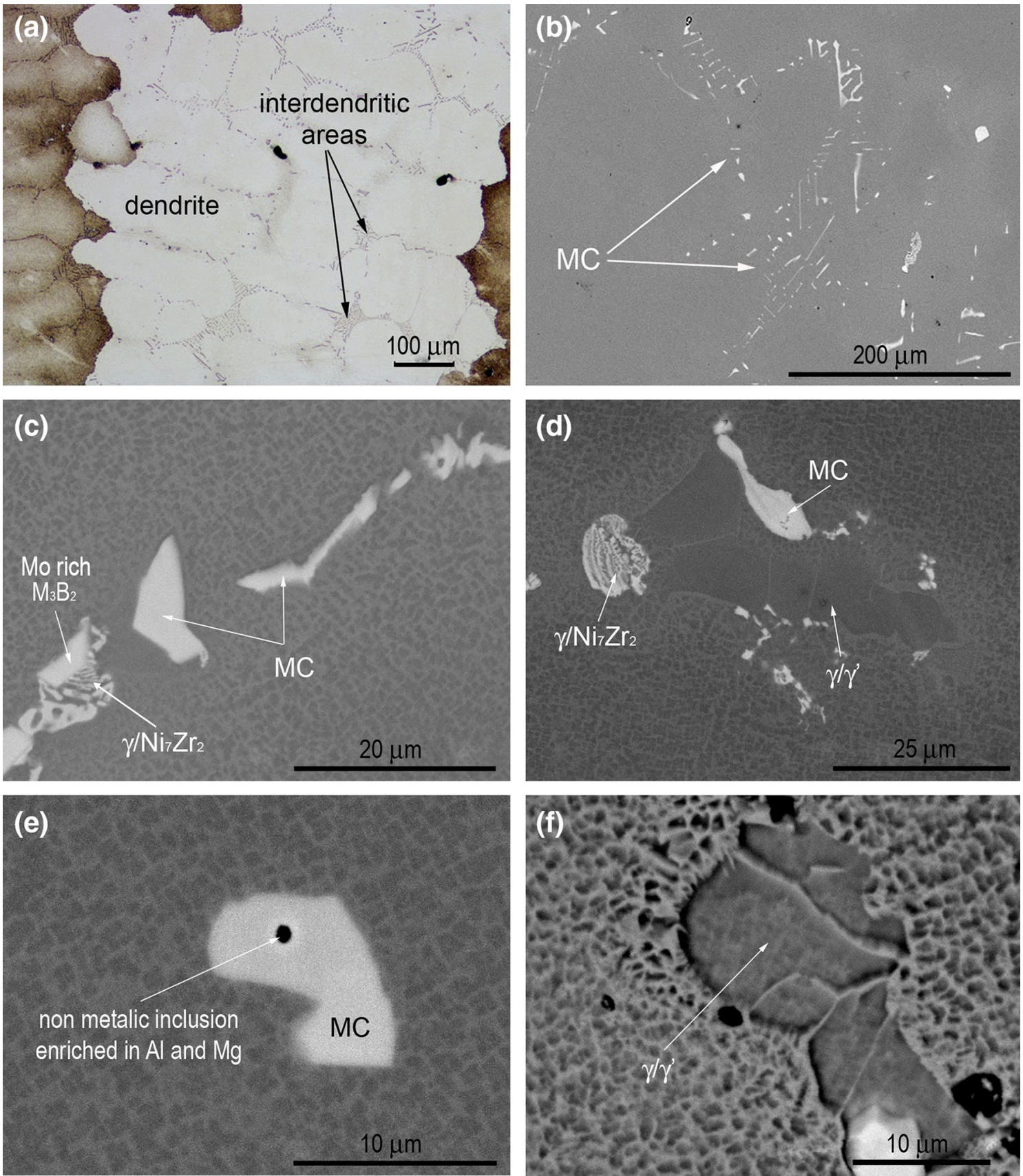

Fig. 5. LM (a) and SEM (b-f) images of the IN713C superalloy microstructure.

were observed in the interdendritic areas, as shown in Fig. 8. Such tendency is commonly observed in cast nickel-based superalloys. ${ }^{30-32}$

\section{TEM Analysis}

TEM images (bright field) representative of the alloy $\gamma$-matrix, a eutectic mixture in which one phase is rich in $\mathrm{Ni}$ and $\mathrm{Zr}$, and precipitates of a phase rich in Mo are shown in Figs. 9 and 10, respectively.

The results of the SAED analysis corresponding to the microstructure images are given in Figs. 9 and 11 and in Table V. On the basis of the obtained results, it can be stated that the alloy matrix is a $\gamma-\mathrm{Ni}$ solid solution strengthened by cubic, coherent precipitates of the $\gamma^{\prime}\left(\mathrm{Ni}_{3} \mathrm{AlTi}\right)$ phase. These observations are in agreement with the literature data. ${ }^{2,13}$

It was found that the phase rich in $\mathrm{Ni}$ and $\mathrm{Zr}$ is $\mathrm{Ni}_{7} \mathrm{Zr}_{2}$ (Table V). It has a monoclinic structure (mC36; $\mathrm{C} 2 / \mathrm{m}(12))$, with $\mathrm{a}=4.698 \AA, \mathrm{b}=8.235 \AA$, $\mathrm{c}=12.193 \AA$, and the angle $\beta=95.83^{\circ}$. The following crystallographic relationships between the $\mathrm{Ni}_{7} \mathrm{Zr}_{2}$ phase and the $\gamma$ matrix were identified:

[013] $/ /[21-1] \mathrm{Ni}_{7} \mathrm{Zr}_{2}$ and $(-13-1) \gamma / / \sim(022) \mathrm{Ni}_{7} \mathrm{Zr}_{2}-$ see Fig. 11a 
(a)

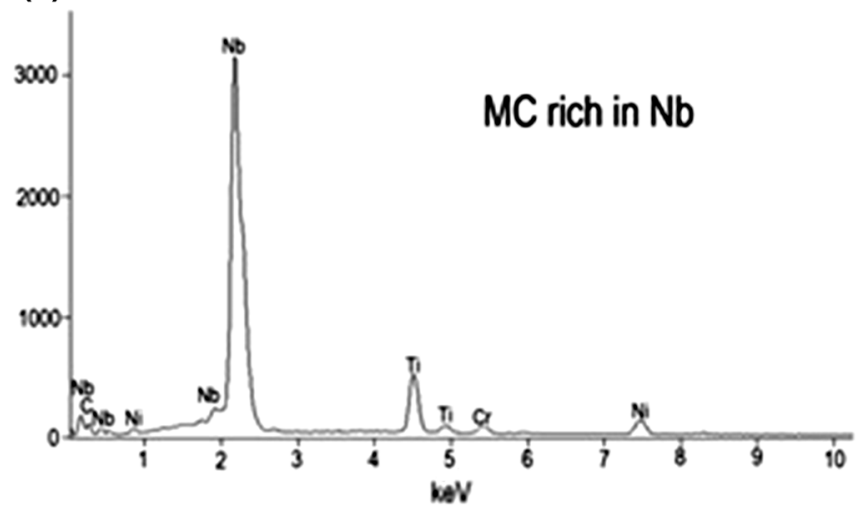

(c)

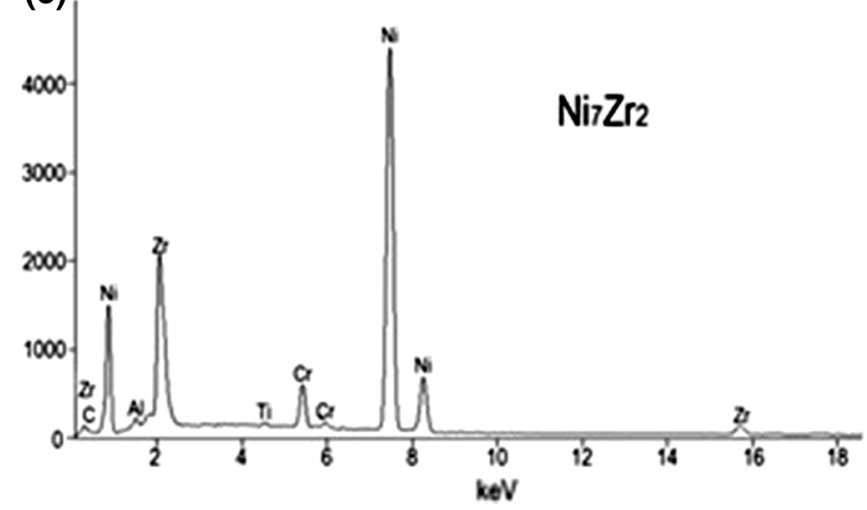

(b)

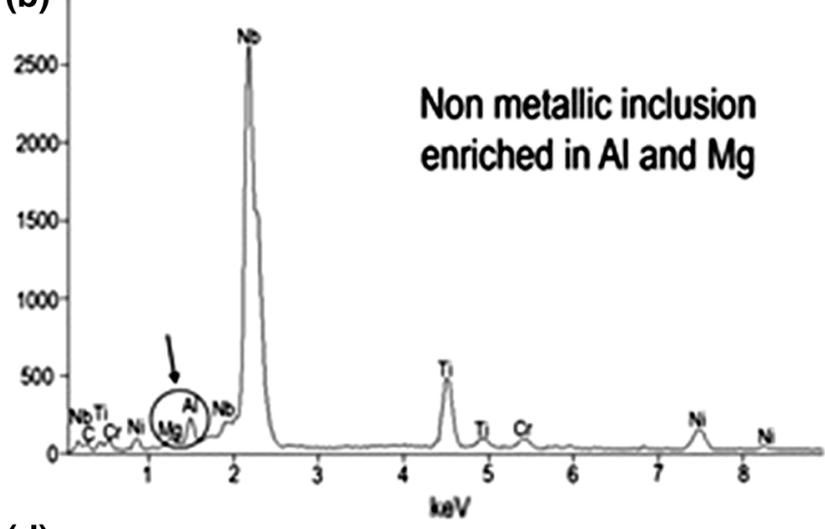

(d)

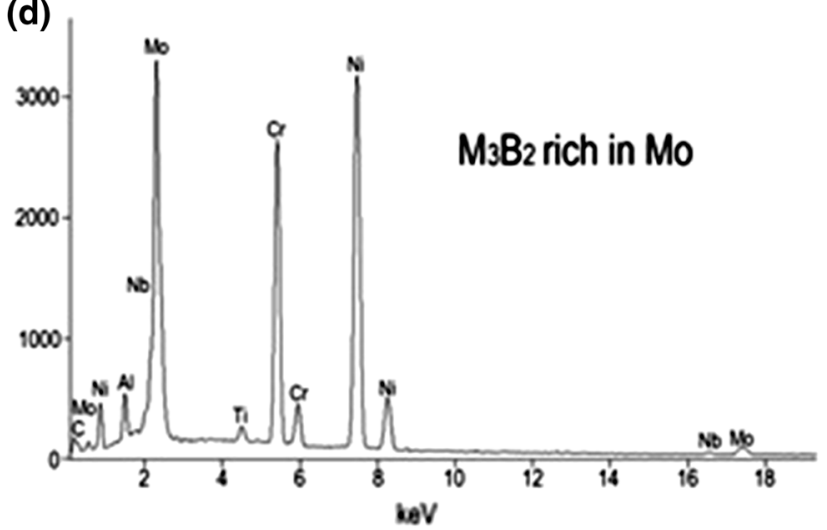

Fig. 6. Spectrograms for $\mathrm{NbC}$ (a), nonmetallic inclusion rich in $\mathrm{Al}$ and $\mathrm{Mg}$ observed in the cores of $\mathrm{NbC}$ carbides (b), $\mathrm{Ni}_{7} \mathrm{Zr}_{2}(\mathrm{c})$, and $\mathrm{M}_{3} \mathrm{~B}_{2}$ (d).

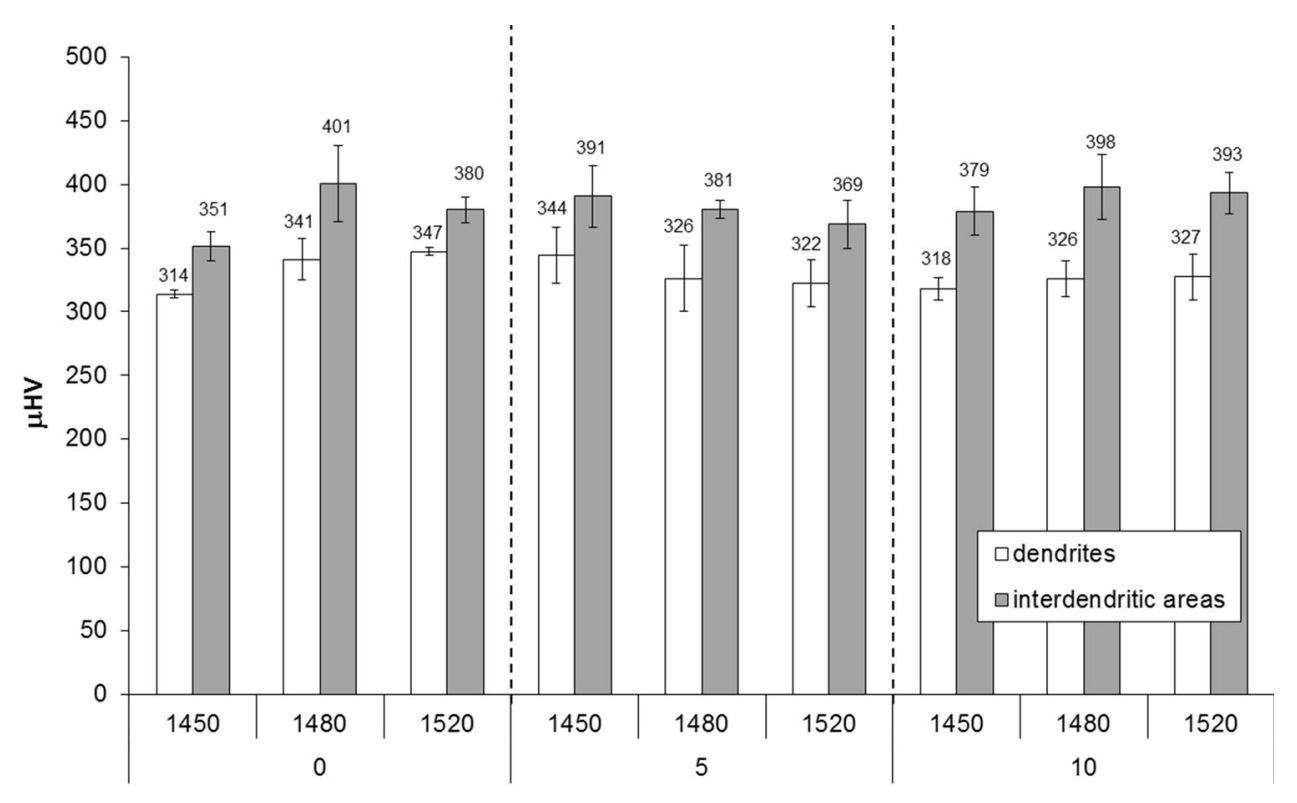

$\mathbf{T}_{\mathrm{m}}\left[{ }^{\circ} \mathrm{C}\right]$ / inoculant content [\%wt.]

Fig. 7. Microhardness of the dendrites and the interdendritic areas for different melt-pouring temperatures and $\mathrm{CoAl}_{2} \mathrm{O}_{4}$ contents. 
Table IV. Segregation of main alloying elements in the IN 713C superalloy

\begin{tabular}{|c|c|c|c|c|c|c|}
\hline \multicolumn{2}{|l|}{ Trial parameters } & \multicolumn{5}{|c|}{$k=C_{\mathrm{D}}^{\mathrm{i}} / C_{\mathrm{ID}}^{\mathrm{i}}$} \\
\hline $\mathrm{CoAl}_{2} \mathrm{O}_{4}$ content $(\mathrm{wt} . \%)$ & $\boldsymbol{T}_{\mathbf{m}}\left({ }^{\circ} \mathrm{C}\right)$ & Al & $\mathbf{T i}$ & $\mathbf{C r}$ & Mo & $\mathbf{N b}$ \\
\hline \multirow[t]{3}{*}{0} & 1450 & 1.19 & 0.93 & 0.92 & 0.76 & 0.73 \\
\hline & 1480 & 1.07 & 1.01 & 0.93 & 0.78 & 0.82 \\
\hline & 1520 & 1.03 & 0.90 & 0.99 & 0.85 & 0.59 \\
\hline \multirow[t]{3}{*}{5} & 1450 & 1.03 & 1.10 & 0.99 & 0.91 & 0.94 \\
\hline & 1480 & 1.09 & 0.88 & 0.93 & 0.79 & 0.75 \\
\hline & 1520 & 1.08 & 0.89 & 0.97 & 0.85 & 0.89 \\
\hline \multirow[t]{3}{*}{10} & 1450 & 1.11 & 0.95 & 0.91 & 0.73 & 0.53 \\
\hline & 1480 & 1.13 & 1.00 & 0.84 & 0.78 & 0.63 \\
\hline & 1520 & 1.04 & 0.95 & 1.02 & 0.66 & 0.64 \\
\hline
\end{tabular}

$C_{\mathrm{D}}^{\mathrm{i}}$ stands for the element concentration in dendrite and $C_{\mathrm{ID}}^{\mathrm{i}}$ for the element concentration in interdendritic areas.

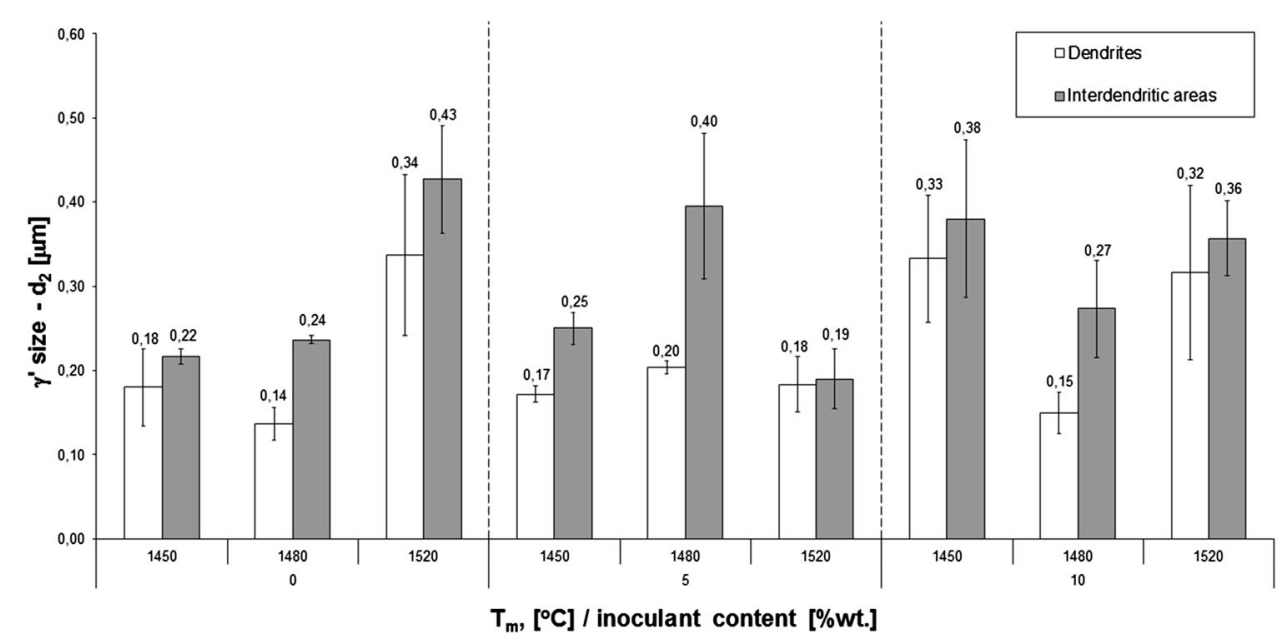

Fig. 8. Size of the $\gamma^{\prime}$ phase precipitates in the dendrites and the interdendritic areas for different melt-pouring temperatures and $\mathrm{CoAl}_{2} \mathrm{O}_{4}$ contents.

$[-112] \gamma / /[101] \mathrm{Ni}_{7} \mathrm{Zr}_{2}$ and $(-11-1) \gamma / / \sim(-202) \mathrm{Ni}_{7} \mathrm{Zr}_{2}$ - see Fig. $11 b$

$[011] \gamma / /[201] \mathrm{Ni}_{7} \mathrm{Zr}_{2}$ and $(-200) \gamma / / \sim(-204) \mathrm{Ni}_{7} \mathrm{Zr}_{2}$ - see Fig. 11c

The phase rich in $\mathrm{Mo}_{0}$ is $\mathrm{M}_{3} \mathrm{~B}_{2}$ boride with a tetragonal lattice (tP10, F4/mbm) and $\mathrm{a}=\mathrm{b}=5.775 \AA$ and $\mathrm{c}=3.145 \AA$.

\section{DISCUSSION}

\section{Influence of $T_{m}$ on SDAS and Surface Grain Size}

The secondary dendrite arm spacing is correlated with the local solidification time $t_{S O L}$, cooling rate, temperature gradient $G$, and solidification rate $v$ (Eq. 1). ${ }^{33}$ The cooling rate, thermal gradient, and solidification rate are determined by the thermophysical properties of the alloy and shell mold, the casting process conditions (e.g., melt-pouring temperature, shell temperature, temperature of the shell cooling chamber after casting, casting, and shell wall cross-section thicknesses), and the heat transfer coefficients between the casting and shell mold:

$$
\operatorname{SDAS} \sim\left(t_{S O L}\right)^{1 / 3} \sim\left(\frac{1}{G v}\right)^{1 / 3}
$$

In the present study, no evidence for correlation between SDAS and the melt-pouring temperature or the inoculant content was found (Fig. 4). The works $^{21,22}$ present results that show that when the melt-pouring temperature is constant and the variable is the inoculant content, there are no meaningful differences between SDAS values, despite significant differences in the grain size, which is confirmed by our results. It means that if the constant melt-pouring temperature cooling rate, thermal gradient, and solidification rate are constants, the introduction of inoculant to the prime coat is negligible. However, an increase in the meltpouring temperature accompanied by a decrease in the cooling rate will be manifested in an increase in 
SDAS. The investment casting of nickel alloys into ceramic molds is characterized by very low cooling rates (in the presented work an average of $10^{\circ} \mathrm{C} / \mathrm{min}$ to $12^{\circ} \mathrm{C} / \mathrm{min}$ in the temperature range from $T_{\mathrm{m}}$ to $650^{\circ} \mathrm{C}$ ). It stems from the fact that the ceramic mold has a very low thermal conductivity value (for castings used by the authors, it is $1.09 \mathrm{~W} /(\mathrm{mK})$ at $1200^{\circ} \mathrm{C}$ and $0.77 \mathrm{~W} /(\mathrm{mK})$ at $\left.600^{\circ} \mathrm{C}\right)$. Additionally, heat insulating materials (Fiberfrax ${ }^{\circledR}$ wrapping)

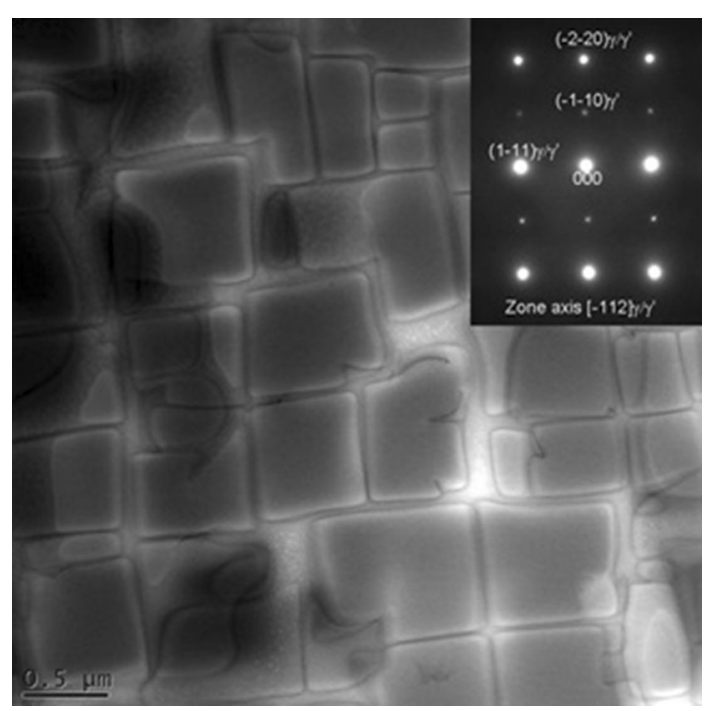

Fig. 9. TEM image (bright field) and corresponding SAED pattern for cubic precipitates of the $\gamma$ ' phase in the matrix of the $\gamma$ phase.

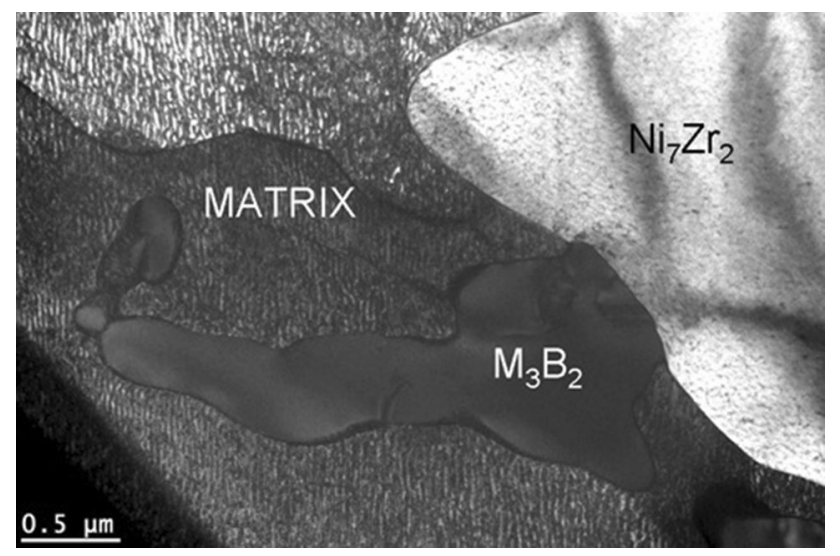

Fig. 10. TEM image (bright field) of Ni7Zr2 and M3B2 phases. were used, which also decreases the cooling rate. Another fact worth mentioning is that the maximum difference between the melt-pouring temperatures is only $70^{\circ} \mathrm{C}$, and the temperature of the mold during casting is quite high $\left(1200^{\circ} \mathrm{C}\right)$.

In the work, ${ }^{33}$ it has been shown for plate castings (width of $40 \mathrm{~mm}$ and thickness of $4 \mathrm{~mm}$ ) of the superalloy IN738LC, a substantial change in temperature gradient occurs in the surface zone of the casting. On the basis of the casting cross section, it has been found that the gradient was $2.75 \mathrm{~K} / \mathrm{mm}$ on the surface and then decreased rapidly away from the surface. At the distance of $10 \mathrm{~mm}$ from the surface, the gradient was $0.25 \mathrm{~K} / \mathrm{mm}$ and remained constant in the central part of the plate. Close to a tenfold decrease in the gradient caused a one-third increase in SDAS, or $30 \mu \mathrm{m}$ in the surface zone and $40 \mu \mathrm{m}$ in the volume of the casting, respectively.

It should also be noted that the mentioned measurements of SDAS were made in the volume of the material and not on its surface, as it was in the case of determining the grain size. By taking into account the parameters of our process discussed earlier (small differences in melt-pouring temperatures, and irrespective of the temperature cooling rates caused by thermophysical properties of the mold material), as well as the area selection for determining SDAS, the minor changes in cooling rate, thermal gradient, and solidification rate in this study provide evidence for a correlation between SDAS and the melt-pouring temperature or the inoculant content. In commercial practice, this means that some scatter between melt-pouring temperatures can be allowed without the consequence of a significant influence on SDAS in the casting volume and, therefore, on its mechanical properties.

It has to be remembered, however, that some significant differences in both the macro- and microstructure of the casting may occur on the surface and in the surface zone in relation to the casting volume for different melt-pouring temperatures, as evidenced by the grain size results in Fig. 4. A rise of $70^{\circ} \mathrm{C}$ in the melt-pouring temperature causes an increase in the grain size on the casting surface of each case analyzed. It is consistent with the expectation that an increase in the melt-pouring temperature lowers the cooling rate and may result in grain coarsening. The differences

Table V. Comparison of the experimental $\left.d_{(\mathrm{hkl}}\right)$ spacings with values from powder diffraction files

\begin{tabular}{lccccccc}
\hline $\mathrm{Ni}_{7} \mathrm{Zr}_{2}$ & $(\mathrm{hkl})$ & $(020)$ & $(022)$ & $(-112)$ & $(1-11)$ & $(113)$ & $(-131)$ \\
& $d_{(\mathrm{hkl})}(\AA)$ & 4.04 & 3.52 & 3.42 & 3.80 & 2.94 & 2.31 \\
& & $4.12^{\mathrm{a}}$ & $3.51^{\mathrm{a}}$ & 3.41 & $3.76^{\mathrm{a}}$ & $2.75^{\mathrm{a}}$ & $2.30^{\mathrm{a}}$ \\
$\mathrm{M}_{3} \mathrm{~B}_{2}$ & $(\mathrm{hkl})$ & $(010)$ & $(111)$ & $(101)$ & $(211)$ & $(110)$ & $(120)$ \\
& $d_{(\mathrm{hkl})}(\AA)$ & 5.72 & 2.49 & 2.76 & 2.00 & 4.07 & 2.56 \\
& & $5.74^{\mathrm{b}}$ & $2.49^{\mathrm{b}}$ & no data & $1.99^{\mathrm{b}}$ & $4.09^{\mathrm{b}}$ & $2.58^{\mathrm{b}}$ \\
\hline
\end{tabular}

${ }^{\mathrm{a} P D F} 71-0543 .{ }^{\mathrm{b}} \mathrm{PDF}$ 18-0839. 

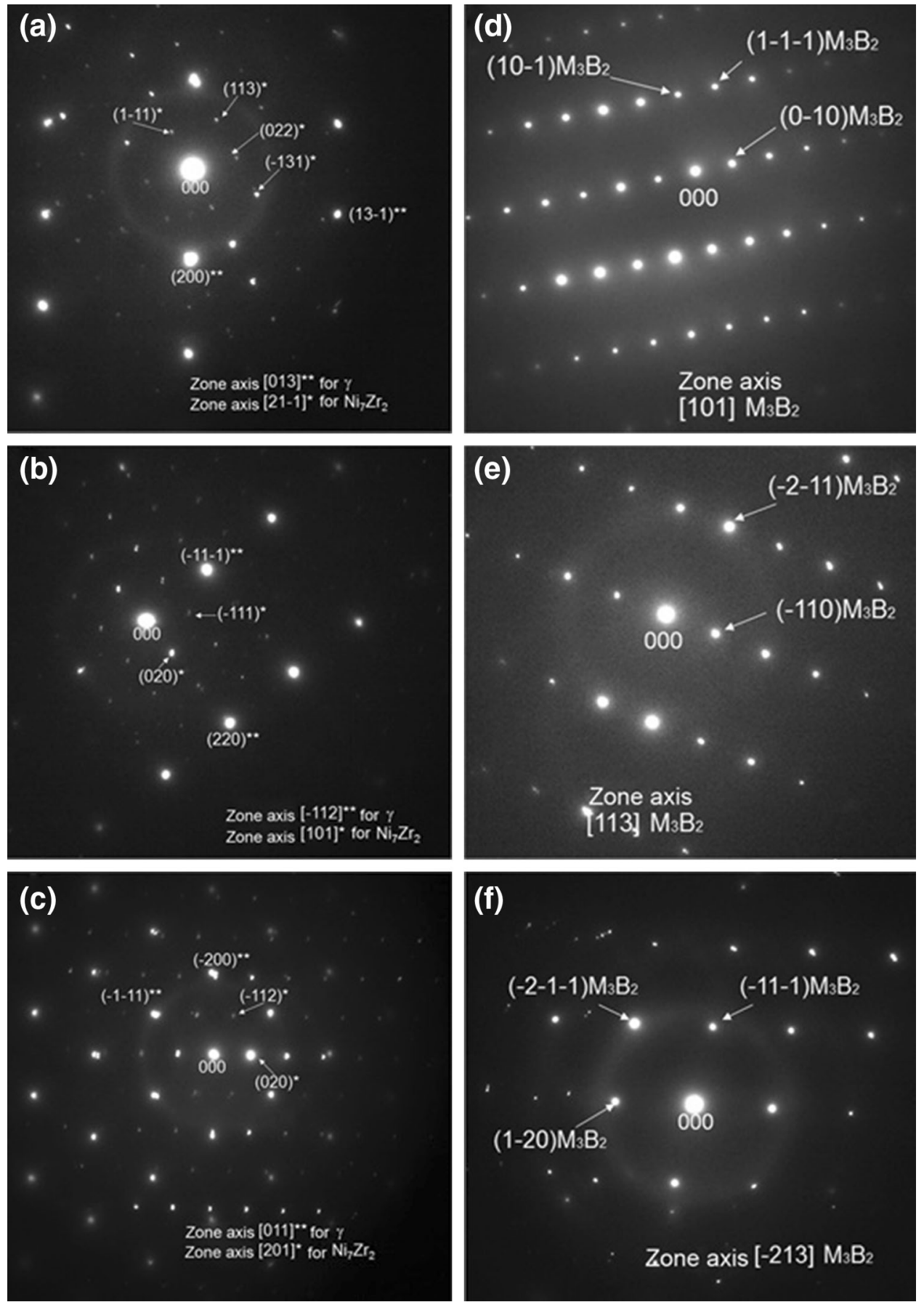

Fig. 11. SAED patterns for precipitations of Ni7Zr2 $(a-c)$ and M3B2 $(d-f)-$ corresponding to Fig. 10.

in macro- and microstructure (SDAS, morphology, and the size of constituents and $\gamma$ 'precipitates) in the surface zone and in the volume of the casting will be the topic of our next study.

\section{Refining Mechanism of Surface Macro Grains}

The modification mechanism of nickel alloys with the use of cobalt aluminate is widely discussed in the literature. ${ }^{19-24}$ The alloying elements react with
$\mathrm{CoAl}_{2} \mathrm{O}_{4}$. As a result of the process on the surface of the shell mold, Co particles are formed that act as nucleation cites for heterogeneous crystallization of the $\gamma$ phase ( $q$ is the latent heat of the presented reactions):

$$
\begin{gathered}
\mathrm{CoAl}_{2} \mathrm{O}_{4}+2 / 3 \mathrm{Cr} \rightarrow 1 / 3 \mathrm{Cr}_{2} \mathrm{O}_{3}+\underline{\mathrm{Co}}+\mathrm{Al}_{2} \mathrm{O}_{3}+\mathrm{q} \\
\mathrm{CoAl}_{2} \mathrm{O}_{4}+2 / 3 \mathrm{Al} \rightarrow 3 / 4 \mathrm{Al}_{2} \mathrm{O}_{3}+\underline{\mathrm{Co}}+\mathrm{q}
\end{gathered}
$$




$$
\mathrm{CoAl}_{2} \mathrm{O}_{4}+1 / 2 \mathrm{Ti} \rightarrow 1 / 2 \mathrm{TiO}_{2}+\underline{\mathrm{Co}}+\mathrm{Al}_{2} \mathrm{O}_{3}+\mathrm{q}
$$

At a temperature above $450^{\circ} \mathrm{C}$, cobalt has the same crystallographic system (FCC) as the IN713C matrix ( $\gamma$ phase). The lattice constants of both phases, $a_{\mathrm{Co}}=3.5447 \mathrm{~A}$ and $a_{\gamma}=3.5975 \mathrm{~A}$, are similar, and the lattice misfit (defined as $f=\frac{a_{\gamma}-a_{\mathrm{Co}}}{a_{\mathrm{Co}}} 100 \%$ ) of the nucleation sites $(\mathrm{Co})$ and the $\gamma$ phase equal only $1.5 \%$. The similarity of crystallographic systems and a low value of lattice misfit guarantees effective refinement of the surface macrograins. ${ }^{25}$

In earlier studies ${ }^{23,24}$ it has been confirmed that Co-generated nucleation sites are mainly observed on the surface of the shell mold and that their size reaches up to $4 \mu \mathrm{m}$. In Ref. 24 , it has also been shown that as a result of the modification, there is a refinement of Co to a depth of about $10 \mu \mathrm{m}$. It should be noted, however, that in this case the prime coat of the shell mold contained only $\mathrm{CoAl}_{2} \mathrm{O}_{4}$ and a binder. In Ref. 34 the depth of the refinement was only $0.01 \mu \mathrm{m}$ for $10 \%$ inoculant content. This is substantiated by the fact that the effectiveness of the modification significantly decreases with distance from the surface of the casting. Thus, this type of modification is not applicable for thick-walled castings.

In contrast, the unquestionable advantage of this type of modification is the fact that the $\mathrm{CoAl}_{2} \mathrm{O}_{4}$ reduction reaction is an exothermic reaction, which effectively prevents the formation of the so-called "chill grains" considered to be a casting defect. These defects were not observed in our castings.

As it has already been mentioned, for castings that underwent modification and an increase of $T_{\mathrm{m}}$, there is an increase in the grain size. In the case of unmodified castings, the grain size increases 2.3 times. For modified castings, it increases 1.8 and 1.4 times for $5 \%$ and $10 \%$ inoculant content, respectively. An increase in the grain size is primarily associated with a decrease in the cooling rate during increasing $T_{\mathrm{m}}$; it can be, however, supposed that in the case of high melt-pouring temperatures (and a relatively high temperature of the shell mold), some nucleation cites can be remelted, which would also contribute to the increase of the grain size. Consequently, the increase in the inoculant content, while applying high $T_{\mathrm{m}}$, is desirable. Additionally, when $\mathrm{CoAl}_{2} \mathrm{O}_{4}$ content in the prime coat is increased, a greater number of nucleation cites may be "generated." If some of them remelt, then a sufficiently large number of nucleation cites remains, ensuring grain refinement.

\section{Microstructure Constituents and Solidification Path}

Based on the DTA investigations and microstructure characteristic of the IN713C superalloy, it may be concluded that in the first stage of solidification, $\gamma$-phase crystals are formed. Next, with the decrease of temperature, the solubility of alloying elements (such as $\mathrm{Nb}, \mathrm{Mo}, \mathrm{Ti}, \mathrm{C}$, and $\mathrm{B}$ ) in the $\gamma$-phase is reduced, which is manifested by their segregation at the $\gamma$-phase dendrite-interdendritic liquid interface. Favorable conditions for the precipitation of $\mathrm{NbC}$ primary carbides occur (according to the typical reactions $\mathrm{L} \rightarrow \mathrm{MC}$ or $\mathrm{L} \rightarrow \gamma+\mathrm{MC}$ ) in the interdendritic areas. These areas offer some solubility of other carbide-forming elements, such as $\mathrm{Ti}, \mathrm{Mo}$, or $\mathrm{Cr}$. The precipitation of $\mathrm{MC}$ in the interdendritic liquid depletes these elements and enriches them with $\mathrm{Al}$ and $\mathrm{Ti}-$ the elements that are $\gamma^{\prime}$ formers.

In the final stage of solidification, a eutectic reaction $L \rightarrow \gamma+\gamma^{\prime}$ in the areas where the interdendritic liquid is enriched with $\mathrm{Al}$ and $\mathrm{Ti}$ takes place. The solubility of $\mathrm{Zr}$ and $\mathrm{B}$ in $\gamma$ and $\gamma^{\prime}$ is extremely low, ${ }^{31,32,35,36}$ and thus, the aforementioned elements segregate into the boundary $\left(\gamma / \gamma^{\prime}\right)$ eutectic-residual liquid interface, thus, providing favorable conditions for the precipitation of phases rich in $\mathrm{Zr}$ like $\mathrm{Ni}_{5} \mathrm{Zr}$ or $\mathrm{Ni}_{7} \mathrm{Zr}_{2}$ and phases rich in $\mathrm{B}$ like $\mathrm{M}_{5} \mathrm{~B}_{3}$ or $\mathrm{M}_{3} \mathrm{~B}_{2}$ borides. ${ }^{31,32,35,36}$

On the basis of phase equilibrium ${ }^{37}$ for the binary alloy $\mathrm{Ni}-\mathrm{Zr}$, it can be clearly stated that only one eutectic reaction occurs (which takes place at $1170^{\circ} \mathrm{C}$ ), in which $\mathrm{L} \rightarrow \gamma+\mathrm{Ni}_{5} \mathrm{Zr}$. This stands in clear contrast with our observations.

According to the equilibrium system, ${ }^{37}$ the $\mathrm{Ni}_{7} \mathrm{Zr}_{2}$ phase is formed directly from the liquid at $1420^{\circ} \mathrm{C}$. Next, at $1300^{\circ} \mathrm{C}$ and $1180^{\circ} \mathrm{C}$, two peritectic reactions take place: $\mathrm{L}+\mathrm{Ni}_{7} \mathrm{Zr}_{2} \rightarrow \mathrm{Ni}_{5} \mathrm{Zr}$ and $\mathrm{L}+\mathrm{Ni}_{7} \mathrm{Zr}_{2} \rightarrow$ $\mathrm{Ni}_{21} \mathrm{Zr}_{8}$. It can be concluded that, at ambient temperature, no $\mathrm{Ni}_{7} \mathrm{Zr}_{2}$ phase occurs in the alloy eutectics. This phase might be present in the microstructure but not in the eutectic.

To explain the presence of the $\mathrm{Ni}_{7} \mathrm{Zr}_{2}$ phase in the eutectic, one should refer to the equilibrium systems of multi-element alloys. Examinations of alloy Ni7.9Al-7.7Cr-1.4Mo-1.7Zr-0.008B in Ref. 38 suggest that the residual liquid rich in $\mathrm{Zr}$ reacts with the eutectic phase or the primary phase $\gamma^{\prime}$ according to the peritectic reaction $\mathrm{L}+\gamma^{\prime} \rightarrow \gamma+\mathrm{Ni}_{7} \mathrm{Zr}_{2}$. The eutectic reaction $\mathrm{L} \rightarrow \gamma+\mathrm{Ni}_{7} \mathrm{Zr}_{2}+\mathrm{Ni}_{5} \mathrm{Zr}$ is also possible. ${ }^{38}$ However, in our studies, we did not observe the presence of the $\mathrm{Ni}_{5} \mathrm{Zr}$ phase. This suggests that the lamellar structure of $\gamma / \mathrm{Ni}_{7} \mathrm{Zr}_{2}$ can be a result of the peritectic reaction. It should be noted, however, that in the immediate vicinity of the phase mixture $\gamma / \mathrm{Ni}_{7} \mathrm{Zr}_{2}$, precipitates of $\mathrm{M}_{3} \mathrm{~B}_{2}$ borides were found. In Ref. 39 it was proven that the formation of eutectic $\left(\gamma+\gamma^{\prime}\right)$ may be accompanied by the precipitation (from the residual liquid rich in $\mathrm{Zr}$ and $\mathrm{B}$ ) of a ternary eutectic, according to the equation $\mathrm{L} \rightarrow$ $\gamma+\mathrm{Ni}_{7} \mathrm{Zr}_{2}+\mathrm{M}_{3} \mathrm{~B}_{2}$, which is in agreement with our observations.

\section{CONCLUSION}

The results show that the cobalt aluminate (added in the range of 5-10 wt.\% to the prime coat of the shell mold) significantly reduced the size of the EX grains. Additionally, the presence of an inoculant decreases the size and fraction of the columnar 
grains. However, the increase of the inoculant concentration from 5 wt. $\%$ to 10 wt.\% causes no significant improvement. Also, the increase of the melt-pouring temperature from $T_{\mathrm{m}}=1450^{\circ} \mathrm{C}$ to $T_{\mathrm{m}}=1520^{\circ} \mathrm{C}$ results in an increase in the mean equivalent diameter of the EX grains in all the analyzed cases.

Independent of the melt-pouring temperature, the IN713C superalloy has a nonhomogenous dendritic structure in the as-cast state; however, no significant differences were found between the SDAS. The mean values of SDAS are within the range of $66 \mu \mathrm{m}$ to $89 \mu \mathrm{m}$.

The melt-pouring temperature and the inoculant content do influence the phase composition of the alloy. The alloy matrix consists of the $\gamma-\mathrm{Ni}$ phase strengthened by cubic, coherent precipitates of $\gamma^{\prime}-\mathrm{Ni}_{3}(\mathrm{AlTi})$ phase. The interdendritic areas reveal the presence of $\mathrm{NbC}$ primary carbides, as well as that of eutectics: $\gamma+\mathrm{NbC}, \gamma+\gamma^{\prime}$ and $\gamma+\mathrm{Ni}_{7} \mathrm{Zr}_{2}+\mathrm{M}_{3} \mathrm{~B}_{2}$.

Examinations of the chemical composition of the dendrites and interdendritic areas confirmed the segregation of molybdenum, niobium, and chromium into the interdendritic areas, whereas aluminum enriched the cores of the dendrites, regardless of the conditions of the casting process. The segregation of elements of large atomic radii (Nb-146 pm and Mo-137 pm) significantly affects the matrix solid solution strengthening, as well as the size of $\gamma^{\prime}$, which causes an increase in hardness of the interdendritic areas.

\section{ACKNOWLEDGEMENT}

The work was financed with the public resources of the Polish National Centre for Research and Development. The project was accomplished within the frames of the Program INNOTECH-K2/IN2/8/ 181849/NCBR/13, program path IN-TECH.

\section{OPEN ACCESS}

This article is distributed under the terms of the Creative Commons Attribution 4.0 International License (http://creativecommons.org/licenses/by/ 4.0/), which permits unrestricted use, distribution, and reproduction in any medium, provided you give appropriate credit to the original author(s) and the source, provide a link to the Creative Commons license, and indicate if changes were made.

\section{REFERENCES}

1. J.R Brinegar, J.R Mihalisin, J. VanderSluis, Proc. Int. Symp. Super. 53 (1984).

2. F. Zupanic, T. Boncina, A. Krizman, and F.D. Tichelaar, J. Alloy. Compd. 329, 290 (2001).

3. D. Gelmedin and K.H. Lang, Proc. Eng. 2, 1343 (2010).

4. T.M. Maccagno, A.K. Koul, J.-P. Immarigeon, L. Cutler, R. Allem, and G. L'esperance, Metall. Mater. Trans. A 21, 3115 (1990).
5. N. Elliaz, G. Shemesh, and R.M. Latanision, Eng. Fail. Anal. 9, 31 (2002).

6. M. Tabuchia, K. Kubo, K. Yagi, A.T. Yokobori Jr, and A. Fuji, Eng. Fract. Mech. 62, 47 (1999).

7. A. Ges, H. Palacio, and R. Versaci, J. Mater. Sci. 29, 3572 (1994).

8. G.A. Kool, J. Thermal Spray Technol. 5, 31 (1996).

9. C. Persson and P.-O. Persson, J. Mater. Eng. Perform. 2, 565 (1993)

10. A.K. Bhambri, T.Z. Kattamis, and J.E. Morral, Metall. Trans. B 6B, 523 (1975).

11. A. Somoza, G. Santos, A. Ges, R. Versaci, and F. Plazaola, Phys. Stat. Solidi (a) 174, 189 (1999).

12. M. Lachowicz, W. Dudziński, K. Haimann, and M. PodrezRadziszewska, Mater. Sci. Eng. A 479, 269 (2008).

13. M. Lachowicz, W. Dudziński, and M. Podrez-Radziszewska, Mater. Charact. 59, 560 (2008).

14. M.B. Lachowicz, Arch. Foundry Eng. 10, 11 (2010).

15. C.T. Sims, N.S. Stoloff, and W.C. Hagel, Superalloys II (New York: Wiley, 1987).

16. J.R. Davis, Nickel, cobalt and their alloys (Almere: ASM International, 2000), pp. 68-85.

17. F. Binczyk, J. Śleziona, and A. Kościelna, Arch. Foundry Eng. 9, 13 (2009).

18. F. Binczyk and J. Śleziona, Arch. Foundry Eng. 10, 195 (2010)

19. Y. Xiong, A. Yiping Guo, W. Liu, and L. Liu, Sci. Technol. Adv. Mater. 2, 13 (2011).

20. L. Liu, R. Zhang, L. Wang, S. Pang, and B. Zhen, J. Mater. Process. Technol. 77, 300 (1998).

21. P. Zhijiang, J. Shuqin, Z. Zehai, and L. Yan, China Foundry 7, 121 (2010)

22. L. Liu, T. Huang, Y. Xiong, A. Yang, Z. Zhao, R. Zhang, and J. Li, Mater. Sci. Eng. A 394, 1 (2005).

23. W. Jin, F. Bai, T. Li, and G. Yin, Mater. Lett. 62, 1585 (2008).

24. F. Jian and Y. Bin, High temperature alloys for gas turbines, ed. R. Brunetaud (New York: Springer, 1982), pp. 987-997.

25. W. Kurz and D.J. Fisher, Fundamentals of solidification (Dürnten: Trans Tech, 2005).

26. T. Wejrzanowski, M.Sc. Thesis, Warsaw University of Technology, Warsaw, Poland, 2000.

27. S. Zlá, B. Smetana, M. Žaludová, J. Dobrovská, V. Vodárek, K. Konečná, V. Matějka, and H. Francová, J. Therm. Anal. Calor. 110, 211 (2012).

28. W.J. Boettinger, U.R. Kattner, K.-W. Moon, and J.H. Perepezko, Special Publication 960 (Institute of Standards and Technology, 2006).

29. C.J. Burton, TMS Superalloys (1976), p. 147.

30. R.K. Sidhu, O.A. Ojo, and M.C. Chaturvedi, Metall. Mater. Trans. A 40A, 150 (2009).

31. O.A. Ojo, N.L. Richards, and M.C. Chaturvedi, Scripta Mater. 51, 683 (2004).

32. R.K. Sidhu, O.A. Ojo, and M.C. Chaturvedi, J. Mater. Sci. 43, 3612 (2008).

33. M.M. Franke, R.M. Hilbinger, C.H. Konrad, U. Glatzel, and R.F. Singer, Metall. Mater. Trans. A 42A, 1847 (2011).

34. F. Binczyk, J. Śleziona, and P. Gradoń, Kompozyty 11, 49 (2011).

35. H.R. Zhang, O.A. Ojo, and M.C. Chaturvedi, Scripta Mater. 58,167 (2008)

36. L.O. Osoba, R.G. Ding, and O.A. Ojo, Metall. Mater. Trans. A 43a, 4281 (2012).

37. P. Nash and C.S. Jayanth, Bull. Alloy Phase Diagr. 5, 144 (1984)

38. H.B. Motejadded, M. Soltanieh, and S. Rastegari, J. Mater. Sci. Technol. 27, 885 (2011).

39. S.S. Babu, S.A. David, J.M. Vitek, and M.K. Miller, International Field Emission Society IFES'96 Proceedings of the 43rd International Field Emission Symposium 1996. 